\title{
WHAT WORKS IN CITIZENSHIP AND VALUES EDUCATION: ATTITUDES OF HIGH SCHOOL LEAVERS TOWARDS THE ITORERO TRAINING IN POST-GENOCIDE RWANDA
}

\author{
S. Nzahabwanayo* \\ e-mail: nzahabwanayo@yahoo.fr
}

\author{
J. Divala* \\ e-mail : jdivala@uj.ac.za
}

*Department of Education and Curriculum Studies

University of Johannesburg

Auckland Park, Johannesburg

South Africa

\section{ABSTRACT}

This piece of research contributes to the existing literature on citizenship and values education practices in post-conflict contexts. It set out to investigate ways in which high school leavers (HSLs) appreciate Itorero - a non-formal citizenship and values education platform in postgenocide Rwanda. The purpose of the study was also to establish the best predictor of the success of Itorero training according to HSLs' perceptions. The research to be reported here used a survey questionnaire and focus groups with HSLs. It is revealed that while HSLs are happy with the content, they seem to be displeased with the quality of trainers, organization and training environment. The article also shows that the factor "trainers" consistute the best predictor of the success of Itorero. This finding raises serious concerns because Itorero trainers are seen as deficient in a number of ways. The article raises the question of trainers preparation in citizenship and values education. We argue that there is a tendency to neglect this aspect and assume that everyone can contribute to citizenship and values education. We maintain that the quality of trainers is critical for optimal results in citizenship and values education.

Keywords: citizenship and values education, Itorero, post-genocide Rwanda, high school leavers, attitudes, trainers' preparation.

\section{INTRODUCTION}

It can be argued that the 1994 genocide perpetrated against the Tutsi in Rwanda stemmed from a misconception of citizenship. This claim is made chiefly because citizenship was established on the basis of one's ethnic belonging. A number of studies (e.g. Adejumobi 2001; Kabwete Mulinda 2002; Prunier 1995) show that the colonial rule (both Germans and Belgians) considered Tutsi to be of Hamitic origin. As a result, Tutsi were perceived by other Rwandans 
as invaders, as foreigners and not genuine citizens. In this context, Rwanda cannot promote reconstruction, social cohesion and peace building while turning a blind eye to issues pertaining to citizenship and identity. This tends to suggest that citizenship education is critical to the reconstruction process of post-genocide countries (Davies 2005).

For this reason, in order to enable Rwandans reconnect with values and taboos of their culture, during the 12 November 2007 Cabinet, the Government of Rwanda took a resolution to revive Itorero, a traditional citizenship education program. Itorero was officially inaugurated on 16 November 2007, and later in 2013 it became the National Itorero Commission (NIC) according to the Law No. 41/2013 of 16/06/2013 (2013) determining its mission, organization and functioning. Article 6 of the same law stipulates that the core mission of Itorero consists of "Bringing up a patriotic Rwandan who has values and taboos of the Rwandan culture and who has the culture of Intore". Although all categories of Rwandans are expected to undergo Itorero training, the latter is compulsory for HSLs. A two-phase scheme has been developed for HSLs. The first phase named "Gutozwa" seeks to provide HSLs with moral, political and cultural education for a period of three months. In the course of the second phase name "Urugerero", HSLs are placed in national service or volunteerism activities for a period of seven months (NIC 2012). In the present article, we focus on the theoretical phase and we seek to answer the following questions: What are the ways in which HSLs appreciate Itorero training? What is the best predictor of the success of Itorero training according to HSLs' perceptions?

The present article is premised on the view that the approach used and the training environment in which citizenship and values education take place indicate, to a considerable extent, the nature of "a good citizen" being communicated and values being passed on. In other words, the training environment ethos, culture and climate are immensely revealing; they teach some values and express the picture of a "good citizen" being fostered (Schulz et al. 2008). These aspects surface clearly through an investigation of trainees' attitudes.

The present article contributes to the existing literature on the civic and citizenship contextual framework mainly that which developed by the International Association for the Evaluation of Educational Achievement Civic Education Studies (CIVED 1971, ${ }^{1} 1999^{2}$ ) and the International Civic and Citizenship Study - ICCS $2009^{3}$ (Torney-Purta et al. 2001; Schulz et al. 2008). The article reveals that trainers' competencies (academic and moral) are critical to the success of citizenship and values education. We argue that there is a tendency to neglect teachers' or trainers' academic qualification and moral integrity and to assume that everyone can contribute to citizenship and values education. In view of this situation, based on Kerr's ideas (1999), we raise the following questions: Should teachers/trainers in citizenship and values education be generalists or specialists? Is it trivial to envisage initial and in-service 
training in citizenship and values education for trainers or teachers?

The present article uses the Force Field Theory of Change of Kurt Lewin (1951) as the working theory to investigate and analyze the attitudes of HSLs towards Itorero training. According to this theory, if one wishes to produce change in a social setting, one should identify the forces beneath that change. On the one hand, there are driving forces, that is, forces that contribute positively to the occurrence of the change. In other words, these are forces that move towards a positive region and encourage the change to occur. On the other hand, there are forces that oppose the change, i.e., restraining forces. These are static forces that attempt to maintain the status quo. It is worth noting that it is not enough to identify driving and restraining forces; it is also important to establish the intensity or the magnitude of each force.

As far as this study is concerned, what is at issue is the change to be produced among HSLs undergoing Itorero training. In other words, our concern is to investigate - according to HSLs - the extent to which the Itorero training scheme is well suited to convey values and taboos as part of citizenship education. In view of this, the following items were suggested to HSLs to be assessed as driving or restraining forces: citizenship and values education content, approaches used by trainers, quality and quantity of trainers, learners' prerequisites, training environment in terms of food and accommodation, duration, discussion and deliberation, and the development of critical thinking skills.

Drawing again on the theory of Lewin (1951), for change to be successful, once driving and restraining forces have been identified, there is need to (1) strengthen driving forces, and (2) weaken or eliminate restraining forces. Applied to this study, by virtue of HSLs' assessment, this research indicates (i) concrete actions to be taken for driving forces to be strengthened, and (ii) strategies to be envisaged in order to weaken or eliminate restraining forces.

The article is organized along five sections. In the first instance, general considerations on citizenship and citizenship education are provided. Next, a brief overview of Itorero is given with specific focus on the scheme for HSLs. The methodology informing the study is detailed in the fourth section. The last part of the article is devoted to results and discussion of major findings.

\section{GENERAL CONSIDERATIONS ON CITIZENSHIP AND CITIZENSHIP EDUCATION}

A number of studies have suggested that the concept "citizenship" is contested, complex, and ambiguous (e.g. Oliver and Heater 1994; Ramphele 2001; Riesenberg 1992; Van Gunsteren 1998; Wayne 2004). Despite the intricacies linked to the construct "citizenship", Carr (1991) affirms that contested concepts retain the "uncontested common core" which allows them to convey a certain message. In this regard, drawing on Marshall $(1950,28-29)$ we work with the 
following definition citizenship is "a status bestowed on those who are full members of a community. All who possess the status are equal with respect to the rights and duties with which the status is endowed".

Generally, citizenship education is defined as the transmission of knowledge, skills, values and attitudes that will enable young people to participate meaningfully in the community of which they are part, locally, nationally, and globally (Arthur, Davies and Hahn 2008). According to Torney-Purta et al. $(2001,163)$, citizenship education considers issues such as "national history, constitution and political systems, citizen and human rights, international organizations and relations, economic and welfare, media, environmental issues, and civic virtues".

The mode of delivery of citizenship education is threefold: formal, non-formal, and informal (Arthur, Davies, and Hahn 2008; Chioncel and Jansen 2004). Formal citizenship education goes with certification and usually takes place through explicit education and training in some institutions like the school. It has a well-defined curriculum and a clear structure of assessment. Formal citizenship education can take various modalities: a specific subject; integrated with social science subjects; integrated across all subjects; or an extra-curricular activity (Arthur, Davies and Hahn 2008).

The non-formal citizenship education is seen as a series of organized educational interventions outside the formal system or school. It is a kind of deliberate state intervention in post-school learning (Chioncel and Jansen 2004). As for the informal citizenship education, it refers to the unorganized, unsystematic, and/or unintended lifelong learning at home, work, in group membership and through the media (Chioncel and Jansen 2004). This article considers the non-formal citizenship education in post-genocide Rwanda with a specific focus on the Itorero training program meant for HSLs. In the next section, the landscape of citizenship education in post-genocide Rwanda is very briefly discussed.

\section{CITIZENSHIP EDUCATION IN POST-GENOCIDE RWANDA: FROM 1994 TO PRESENT}

In post-genocide Rwanda, citizenship education (in-school and out-of-school programs) focuses on national identity building. It fosters "Rwandanness" in replacement of ethnic dividing affiliations (Tutsi, Hutu and Twa). In this context, citizenship education is taught in both primary and high school. In primary school, citizenship education is termed "social and religious studies" and is taught from Primary 1 to Primary 6 with the weight of four periods per week ( 1 period $=40$ minutes). In lower secondary, citizenship education under the name "history and citizenship" is taught with the weight of three periods per week (REB 2015). 
In addition to formal schooling, there are a number of other institutions in charge of citizenship education. These include the National Unity and Reconciliation Commission (NURC), the Rwanda Demobilization and Reintegration Commission (RDRC), the National Electoral Commission (NEC), and the National Commission for the Fight against Genocide [Commission Nationale de Lutte contre le Génocide - CNLG]. Above these institutions, the National Itorero Commission (NIC) was established with a specific mandate to educate Rwandans for citizenship. In the paragraphs to follow, the revived Itorero is considered with a specific focus on the scheme devised for HSLs.

\section{THE REVIVED ITORERO: A PLATFORM FOR EDUCATING HSLS}

A number of studies (e.g. Codère 1973; Maison des Jeunes de Kimisagara 2008 ; Ndaruhutse 2008; Vansina 2004) indicate that Itorero existed well before colonialism. It was a forum for military training and sport. In other words, Itorero was a place for training a professional army. However, Itorero considered also other domains of education: moral (values and taboos of the Rwandan culture), political (vision and policies of the Rwandan kingdom), cultural (traditional songs and dances), and linguistic (poetry, debate and rhetoric). In the revived Itorero, moral and political education take the center stage. Taboos have also been defined. They include issues like shedding blood, inattention to result, avoidance of accountability, lack of trust, being covetous, etc. (NURC 2009).

In relation to moral education, the NIC has developed a list of seven values to be known and implemented by every Rwandan. These are Rwandanness, patriotism, integrity, courage, self-sacrifice, love for a well-done work, and upholding one's dignity (NURC 2009).

By constrast, political education focuses on the history of Rwanda as well as national development programs mainly Vision 2020, and Economic Development and Poverty Reduction Strategy I and II (EDPRS I and II). These programs are meant to uplift Rwanda from poverty to a middle income country by 2020 . With regard to the history of Rwanda, a distinction is made between three periods: the pre-colonial Rwanda or "Golden age"; the "dark age" (colonial rule: 1899-1962, first and second republics: from 1962 to 1994); and the "renaissance" (1994 to present) (Sundberg 2014). It is worthy noting that while the training of other categories of Rwandans depends on the availability of financial means, all HSLs (university entrants and the rest) are invariablly trained each year.

The Itorero scheme for HSLs comprises two phases: theoretical and practical. A twomonths theoretical phase puts an emphasis on moral and political education described earlier. It is concluded by a four-days intensive training in various sites countrywide. The second phase is community service in the course of which HSLs engage in various activities of public interest 
such as education, health, infrastructure, environment and conservation, safety and security, governance and leadership (NIC 2011). In this article, we focus only on the theoretical phase. A particular attention is given to moal and values education as part of citizenship education. In the paragraph to follow, the methodology informing the present study is described.

\section{METHODOLOGY}

The present research follows the exploratory and correlational design. It is a quantitativequalitative study. It engaged with HSLs who underwent the Itorero training mostly in 2013 and were in level one in 2015 at private and public higher learning institutions in Rwanda. An estimate of 996 HSLs responded to the survey questionnaire while 19 HSLs participated in four focus group discussions. The data collection took place in Rwanda from November 2014 through March 2015. The questionnaire for HSLs (which is in the Appendix A) was developed, piloted and validated by the researchers.

In order to investigate HSLs' attitudes towards Itorero training, HSLs were presented with a list of 12 evaluative items/statements. The latter focused on citizenship and values education content, approaches used by trainers, quality and quantity of trainers, learners' prerequisites, training environment in terms of food and accommodation, duration, discussion and deliberation, and the development of critical thinking skills. The 12 items were suggested to respondents to be ranked on a four-point Likert scale $(1=$ strongly disagree; $2=$ disagree; $3=$ agree; and 4 = strongly agree).

For the sake of ensuring reliability, the questionnaire was subjected to Cronbach's Alpha test. The obtained reliability is .78, which is a good score given that the standard is .60 and above. The obtention of this score required deleting one item that reads "I am inconvenienced by the large number of participants". The deletion of this item raised the reliability from .72 to .78. In view of ensuring validity, Principal Component Analysis (PCA) and Confirmatory Factor Analysis (CFA) were conducted on the 10 remaining items. ${ }^{4}$ PCA was performed using SPSS 22 and CFA was carried out by means of AMOS 22.

PCA followed varimax rotation and correlation matrix. It is worth noting that the item "I had required prerequisites to undergo the training" was loading alone ${ }^{5}$ during PCA, which suggests that the item was ambiguous. It is also important to note that when CFA was conducted, the model requested to use "means and intercept method" 6 option. This restriction entailed the deactivation of the modification indices. CFA could only run on this condition. In the final analysis, CFA performed on a four-factor model comprising nine items indicates a good fit with the data whereby the CFI is .96, and RMSEA is .05. Due to the use of the "means and intercept method", the GFI was omitted in the text output. The obtained goodness-of-fit is 
acceptable. PCA and CFA results are in the Appendices B and C, respectively.

\section{RESULTS}

The extent to which each scale is appreciated by HSLs - who graduated from Itorero training - is indicated in Table 1.

Table 1: Descriptive statistics for scales on attitudes of HSLs

\begin{tabular}{|l|c|c|c|c|c|}
\hline \multicolumn{1}{|c|}{ Scale } & Mean & SD & Min. & Max. & Skewness \\
\hline 1. Content & 10.92 & 1.35 & 3 & 12 & -1.51 \\
\hline 2. Trainers & 6.31 & 1.36 & 2 & 8 & -.72 \\
\hline 3. Organization & 5.45 & 1.52 & 2 & 8 & -.22 \\
\hline 4. Training environment & 4.82 & 1.77 & 2 & 8 & -.00 \\
\hline 5. Overall attitudes HSLs & 27.51 & 4.23 & 10 & 36 & -.38 \\
\hline
\end{tabular}

It is apparent from Table 1 that HSLs are satisfied with the content provided in Itorero; the mean for this factor is $10.92(\mathrm{SD}=1.35)$ with scores ranging between 3 and 12 . The factor "content" includes the knowledge of Rwandan values and taboos; the knowledge required to be a good Rwandan citizen; and the encouragement of critical thinking skills. The implication from this finding is that, according to HSLs, Itorero is efficient in these three aspects: it successfully provides the knowledge of Rwandan values and taboos; it equips HSLs with required knowledge to be good Rwandan citizens; and it allows them develop their critical thinking skills ${ }^{7}$. Itorero is therefore commended for this achievement.

However, results indicate that HSLs seem particularly dissatisfied with trainers, because the mean is $6.31(\mathrm{SD}=1.36)$, with scores ranging between 2 and 8 . These results suggest that there might be problems with either the quantity or quality of trainers, which calls for further investigation. It is worth noting that the situation worsens when it comes to the "organization" where the mean is 5.45 ( $\mathrm{SD}=1.52)$ with scores ranging between 2 and 8 . The "training environment" is no better; it has the mean of $4.82(\mathrm{SD}=1.77)$ with scores ranging between 2 and 8 . These findings tend to suggest that there might be serious problems with the organization and training environment of the Itorero training meant for HSLs. The factor "organization" refers to the adequacy of the training duration and the encouragement of discussion and deliberation in the course of the training. As for the "training environment" factor, it incorporates questions of quality of accommodation, food, etc.

In short, results indicate that while HSLs are happy with the content, they seem to be displeased with trainers, organization and training environment, which arguably calls for further consideration. It is for this reason that the overall appreciation of Itorero training does not fare better: the mean is 27.51 ( $\mathrm{SD}=4.23)$, with scores ranging between 10 and 36 . At this juncture, 
one may ask whether the assessment provided by HSLs is unanimous or reflects only the opinion of a certain group of respondents.

\section{DOES THE HSLS' ASSESSMENT VARY WITHIN SUBGROUPS?}

The present study sought to establish whether the appreciation of the five scales (trainers, content, training environment, organization, and overall attitudes) by HSLs vary within subgroups, i.e., according to gender, marital status, age and training periods. In view of this, parametric inferential techniques (independent t-Test and ANOVA) were used, given that normality and homogeneity of variance were assumed.

In relation to gender, there is a statistically significant difference between males and females in their appreciation of all five components $(p=.000 ; \alpha=.05)$. The situation regarding gender goes as shown in Table 2 below:

Table 2: Comparison of five scales on HSLs' appreciation according to gender

\begin{tabular}{|ll|c|c|c|c|}
\hline \multicolumn{1}{|c|}{ Scale } & T-test & Cohen's D score & Mean/Male & Mean/Female \\
\hline 1. & Trainers & $\mathrm{t}_{985}=-5.525$ where $p=.000$ & .35 & 6.07 & 6.55 \\
\hline 2. & Content & $\mathrm{t}_{988}=-5.026$ where $p=.000$ & .33 & 10.70 & 11.14 \\
\hline 3. & Organization & $\mathrm{t} 980_{9}=-4.968$ where $p=.000$ & .31 & 5.22 & 5.69 \\
\hline 4. & Environment & $\mathrm{t}_{986}=-3.827$ where $p=.000$ & .24 & 4.61 & 5.04 \\
\hline 5. & Overall attitudes & $\mathrm{t}_{972}=-6.918$ where $p=.000$ & .44 & 26.61 & 28.44 \\
\hline
\end{tabular}

It is evident from Table 2 that female HSLs appreciate trainers, content, organization and the training environment more than their male counterparts. However, this difference in appreciation, though statistically significant, is very slight, specifically with regard to the environment, because the effect size is small (Cohen's D score $=.24$ ). In relation to trainers, content and organization, the effect size is medium (Cohen's D scores are respectively $.35, .33$ and .31). These results suggest that though there is a statistically significant difference between males and females in their appreciation of trainers, content, organization and environment, that difference is not carrying great weight.

With regard to marital status and age-group, this study shows that in the appreciation of the four scales (trainers, content, organization and environment) no statistically significant difference was found between (i) married and single HSLs; and (ii) HSLs in various age groups. Rather, a statistically significant difference was found in the appreciation of the training environment across training periods particularly between the year 2014 and other periods, and the year 2013 and other periods, with $F_{982}=4.83$ where $p=.008$. The mean of the training environment for the year 2014 is 4.63 ( $\mathrm{SD}=1.75)$; for the year 2013 it is 4.72 ( $\mathrm{SD}=1.74)$; and 
for other periods $(2012,2011$, and 2010) the mean is 5.09 ( $\mathrm{SD}=1.82)$. However, the effect size is weak $\left(\eta^{2}=.01\right)$. These results suggest that the training environment is slowly deteriorating (notice the decrease in value for the mean of the training environment). In other words, as years go on, the training environment becomes uncomfortable. In fact, owing to the 12 Year Basic Education Program (12 YBE), the number of HSLs is increasing. As a result, there is a congestion on training sites, which makes it difficult to provide appropriate accommodation. The appreciation of other factors (trainers, content, and organization) does not vary across training periods.

When comparing overall attitudes, with regard to gender, a statistically significant difference was found between males and females. In fact, females are more appreciative than males. The mean for females is $28.44(\mathrm{SD}=3.83)$ while the mean for males is $26.61(\mathrm{SD}=$ 4.41). The effect size is medium, because Cohen's D score is .44. The implication is that overall, female HSLs are more satisfied with the Itorero training scheme than their male counterparts. In relation to marital status, age group and training period no statistically difference was found in overall attitudes. In other words, the overall appreciation of the Itorero training scheme does not vary with marital status, age group and training period.

At this juncture, the question arises: According to HSLs' perceptions, which of the four factors (content, trainers, organization and training environment) constitutes the best predictor of the overall success of the Itorero training?

\section{IDENTIFICATION OF THE BEST PREDICTOR OF ITORERO SUCCESS}

The present study sought to scrutinize attitudes of HSLs by investigating the best predictoramong the four factors - of the overall success of the Itorero training. To this end, a multiple regression technique was used by means of the software SPSS. Put differently, on the assumption that the best available rating of the Itorero training scheme for HSLs is the overall perception of its success ("Overall, the Itorero training is a success"), the latter is used as the dependent variable $(Y)$, and a regression equation predicting $Y$ on the basis of four predictors $\left(\mathrm{X}_{1}, \mathrm{X}_{2}, \mathrm{X}_{3}, \mathrm{X}_{4}\right)$ is derived as follows: $\hat{\mathrm{Y}}=\mathrm{b}_{1} \mathrm{x}_{1}+\mathrm{b}_{2} \mathrm{X}_{2}+\mathrm{b}_{3} \mathrm{X}_{3}+\mathrm{b}_{4} \mathrm{X}_{4}+\mathrm{a}$, whereby $\mathrm{x}_{1}$ refers to the content; $\mathrm{x}_{2}$ corresponds to trainers; $\mathrm{x}_{3}$ stands for the organization; and $\mathrm{x}_{4}$ represents the training environment. In this equation, following letters are to be understood this way: $\hat{\mathbf{Y}}$ is the predicted value of the success of the Itorero training scheme for HSLs; $\mathbf{x}$ is the predictor; $\mathbf{b}$ is the slope, i.e., the amount of change in the criterion or the predicted $(Y)$ produced by a one-unit change in the predictor $(X)$; and a the intercept, i.e., the value of $Y$ when $X$ is equal to zero.

It is worth noting that while running multiple regression, except homoscedasticity, linearity and independence of errors, the two remaining assumptions, i.e., multicollinearity and 
normal distribution of errors were met. We tried to remove outliers by means of Mahalanobis and Cook's distance and it made little difference. The null hypothesis $\left(\mathrm{H}_{0}\right)$ to be tested here is that all four predictors (factors) have no impact on the overall success of the Itorero training. In other words, $H_{0}: \beta_{1}=\beta_{2}=\beta_{3}=\beta_{4}=0$. The Table 3 indicates the regression weight of each predicator along with the statistical significance ( $p$-value; $\alpha=.05$ ).

Table 3: Best predictors of Itorero success according to HSLs

\begin{tabular}{|ll|c|c|c|}
\hline \multicolumn{1}{|c|}{ Predictors } & Regression weight $(\boldsymbol{\beta})$ & Sig $(\boldsymbol{\alpha}=\mathbf{0 5})$ & $\mathbf{R}^{\mathbf{2}}$ \\
\hline 1. & Trainers & .33 & .00 & \\
\hline 2. & Content & .27 & .00 & .37 \\
\hline 3. & Training Environment & .14 & .00 & \\
\hline 4. & Organization & .04 & .16 & \\
\hline
\end{tabular}

As Table 3 shows, three out of four predictors have a significant impact on the overall success of the Itorero training, which leads to the rejection of the null hypothesis $\left(\mathrm{H}_{0}\right)$. The significant predictors in order of importance are trainers, content and training environment. Put differently, these results can be summarized this way: A multiple regression was run to predict the overall success of the Itorero scheme for HSLs from trainers, content, training environment and organization. Three of these variables (trainers, content and training environment) statistically significantly predicted the overall success of Itorero for HSLs, $F_{978}=142.95$ where $p=.000$, $R^{2}=.37 .{ }^{8}$ Based on these results, the predicted success of Itorero training for HSLs $(\hat{\mathrm{Y}})$ can be expressed with the following equation:

\section{$\hat{Y}=.33$ Trainers +.27 Content +.14 Training environment +.04 Organization +20}

In relation to the weight of each predictor, results indicate that - according to HSLs' perceptions - among the four factors, the best predictor of the success of the Itorero training for HSLs is the factor "trainers" $(\beta=.33)$. This finding is hugely revealing: it actually says that - according to HSLs' perceptions - the quantity and quality of trainers correlate positively and significantly with the overall success of the Itorero training scheme for HSLs. The factor "content" emerged as the second most significant predictor $(\beta=.27)$. The third predictor is the factor "training environment" $(\beta=.14)$. The factor "organization" does not prove a significant predictor (its $p$-value $>.05$ ).

The implication for these findings is that, according to HSLs, for improving and optimizing the output of Itorero, a lot of emphasis should be placed - in order of importance on trainers, the content and training environment. The idea is that, among other things that Itorero should focus on, priority is to be given to trainers, content and training environment. It is therefore important to probe how these factors stand in the actual happening of the Itorero 
training for HSLs. This is done by considering the views of informants on the three factors under investigation. The question is: Based on their lived experiences, how do HSLs appreciate trainers, the content, and the training environment?

\section{IS THE QUANTITY AND QUALITY OF TRAINERS APPROPRIATE?}

This study shows that, according to HSLs, the quantity and quality of trainers constitute the first predictor to correlate positively and significantly with the overall success of the Itorero training scheme for HSLs $(\beta=.33)$. Given this weight, it is important to examine closely the quantity and quality of trainers. In relation to quantity, results from focus group discussions with HSLs indicate that trainers in training sites are in good number. Some participants mentioned that trainers are even more than required, which is likely to pose the problem of coordination. But in general, focus group discussion results suggest that there is no problem in terms of quantity of trainers.

However, results from focus group discussions with HSLs reveal that problems are rife when it comes to the quality of trainers. A couple of things are disclosed here: (i) some trainers sexually are abusing young girls undergoing the Itorero training; and (ii) some trainers are administering forms of harsh and crude corporal punishment. We consider these two issues at length.

\section{The issue of sexual abuse}

One of the most striking results to emerge from focus group discussions with HSLs is that trainers are not well appreciated in terms of quality. Nearly all informants indicate that the moral behaviour of some trainers is appalling. The vast majority of participants emphasize that in many training sites, trainers sexually abuse young girls undergoing the Itorero training. At this juncture, it is worth considering participants' voices:

"It looks like some trainers are not trained at all prior to come and train us. On my training site, there was a site manager, who, in the evening, used to go out with young girls to have sex with them; then he would bring them back very late in the night. That is a big issue. What kind of trainer is he? And yet, he was the site manager! We had come to Itorero to learn values and taboos, and unfortunately some of us were indulged into sexual misconduct! Having sex before marriage is not condoned by Rwandan values; it is a taboo, it is a sin; it is not a value. That man was in the wrong place at the wrong time. His conduct is neither desirable nor acceptable; he does not qualify as a trainer." [P11]

"Some trainers do not observe values and taboos that they teach; they are just lagging behind them. Imagine a trainer who, during the day, teaches you values and taboos; but in the evening the same trainer comes to snatch a young girl from the group, and takes her to take alcohol and have sex. What kind of trainer is he? It was too much .... And when the concerned young girl(s) come(s) 
back late in the night, you could see her drunk; some were sad, others kept quiet, and some others were deeply afflicted." [P35]

The issue of sexual abuse should be addressed with great care. In our view, the case goes beyond affecting the success of Itorero. The idea is that HSLs victims of sexual abuse during the Itorero training are to be identified, medically treated, psychologically supported, and legally compensated. In fact, there is also need to establish whether such sexual abuses and atrocities do not lead to unwanted pregnancies and the transmission of HIV/AIDS among affected young girls. Equally important, culprits are to be identified, prosecuted against and brought to court. Here the onus is on NIC and the Criminal Investigation Department (CID). Referring to the Force Field Theory of Change (Lewin, 1951), it can be argued that the conduct of some trainers constitutes a restraining force to the success of the Itorero scheme for HSLs.

\title{
Interrogating corporal punishment
}

In this study, what is surprising again is that, according to nearly all informants, in most training sites, inhumane, unkind and harsh corporal punishment is inflicted on trainees. In this regard, one informant reports:

\begin{abstract}
"We were given harsh punishment during the Itorero training. I remember that one day, a trainee was punished severely. Indeed, trainers compelled him to do all sorts of things: he was asked to lay down, later he was asked to run, and then he had to bend his head down and put his legs up for quite a long time. Later, they poured cold water on him, and forced him to do much more tiresome things. At the end, the fellow got so exhausted that he could hardly breathe. They had to rush him to the hospital; he was admitted and placed under intensive care. Lucky enough, the guy recovered. That was a sad experience, because the fellow could even die of this mistreatment." [P15]

"We had one trainer who was very cruel. If I were to meet him today, I am not sure whether I would look into his eyes. He used to beat us seriously on the head with a big stick. That was inhumane .... He would not even hesitate to ask you to lay down in dirty places, then he would walk over you on the back with shoes. I remember that one of our colleagues was walked over, and got seriously injured in his sides and taken immediately to the hospital.” [P24]
\end{abstract}

HSLs indicate that some trainers have little or no knowledge of human rights; they beat trainees like animals. A few informants also confess that in the course of the Itorero training, they are subjected to physical and military exercises beyond their capacities, which compromise their physical and psychological health. It can be concluded from the evidence of focus group discussions with HSLs that some Itorero trainers inflict corporal punishment that compromises the dignity and respect of trainees. This also constitutes a serious restraining force (Lewin 1951) for the success of the Itorero scheme for HSLs. Further investigation is to be conducted on this issue, because such practices constitute torture, human rights violations and abuses. 
Based on evidence in the form of personal testimony about trainers sexually abusing young girls, and administering harsh corporal punishment to trainees, we claim that the quality of some ${ }^{9}$ Itorero trainers is wanting. This is alarming particularly because, as seen previously, the factor "trainers" is the first predictor to correlate positively and significantly with the overall success of the Itorero training scheme for HSLs $(\beta=.33)$. The implication is that - in HSLs' perceptions - having morally problematic trainers is likely to affect tremendously the success of the Itorero training for HSLs. If this is the situation with trainers, then what about the content?

\section{HOW DO HSLS ASSESS THE CONTENT?}

The overall assessment of the content is very positive. This is very encouraging because according to HSLs the content is the second predictor of the overall success of the Itorero training $(\beta=.27)$. Results from focus group discussions with HSLs indicate that for nearly all participants, the content provided in Itorero allows them successfully: (i) to grasp what it takes to be a good Rwandan citizen; (ii) to know Rwandan values and taboos; and (iii) to be purified from ethnic ideologies imposed by parents.

In relation to good citizenship, informants (Itorero graduates) confess that, thanks to the content provided in the Itorero training, they came to understand what it means to be a good Rwandan citizen. In their views, the latter amounts to the following: to put the Rwandan identity above all other identities or affiliations; to know and live up to Rwandan values and taboos; to love one's country and being ready to fight and die for it, if necessary; to pursue public interests; to uphold the dignity inherent in oneself and others; and to be economically self-reliant. Nevertheless, results also indicate that other attributes of a good Rwandan citizen are mentioned with much less emphasis. They include finding solutions to one's problems instead of complaining; helping those in need; respecting laws; and joining in the implementation of generative national policies and programs.

Furthermore, nearly all informants admit that the Itorero content emphasizes knowledge of Rwandan values and taboos. Since some HSLs are not well-versed in this, and others were born outside of Rwanda and brought up in foreign cultures, the teaching about Rwandan values and taboos attracts hugely their attention. According to HSLs, the target of the values education provided in the Itorero is to heighten their sense of humanity and foster the Rwandan identity.

In the end, HSLs indicate that the content taught in the Itorero training is informative and satisfactory, because it liberates them from "bad ethnic ideologies received from [their] parents". Consider the following argument advanced by an informant: 
"In our homes, we still hear so many things from our fathers, mothers and guardians. Some of the latter tell that Rwandans are not one - as it is upheld today; they teach that tall people with a sharp nose are Tutsi; short ones with a bold nose are Hutu. Besides, more often than not, we have been instructed not to visit certain families nor interact with their children. It is true; our parents have told us many things, some of which are detrimental to the unity of Rwandans. In this context, if one does not get a chance to undergo the Itorero training and learn that we are one as Rwandans, mostly likely one will grow up guided by those thwarted stereotypes. The Itorero training has set our minds free from the bad ethnic ideologies received from our parents." [P12]

In short, in terms of content, the vast majority of informants admit that they enjoyed the Itorero training. It is worth noting that some participants even wanted the Itorero to go on longer; for them, it ended earlier than wished: "Itorero ended very fast; I wish we could have continued the training, it could even go on for one year ..." [P35]. Using Lewin's (1951) Force Field Theory of Change, it can be argued that - according to HSLs' perceptions - the content constitutes the driving force of the Itorero scheme for HSLs.

\section{IS THE TRAINING ENVIRONMENT CONDUCIVE IN TERMS OF FOOD, ACCOMMODATION, AND SANITATION?}

It is important to engage with the conduciveness of the Itorero training environment understood in terms of adequate food, accommodation and sanitation - because it affects the quality of the training. As discussed previously, this study shows that according to HSLs perceptions the training environment is the third significant predictor of the overall success of the Itorero training $(\beta=.14)$. In fact, as argued earlier, the training environment in which citizenship and values education take place reveals to some extent the image of "a good citizen" being communicated and values being passed on. In other words, the training environment ethos and culture are revealing; they implicitly teach some values and indirectly express the image of a "good citizen" being fostered.

In relation to food, results from focus group discussions with HSLs indicate that, in general, the meals provided in the course of the training are good. It is explained that meals comprise mainly rice, beans, maize, and Irish potatoes. An observation is made that on some occasions meat is served, but maize - nicknamed chicken [Inkoko] - tends to dominate the menu. Nevertheless, some concerns were raised: the quantity is not enough; trainees are not given ample time to enjoy their little food; and in some sites, HSLs on special diet for medical reasons are not properly catered for.

With regard to accommodation, results from focus group discussions with HSLs show that the housing is of more or less good quality. Yet, two comments are worthy considering. First, it is mentioned that there is congestion, i.e., training sites receive the number of trainees which 
is beyond their accommodation capacity. Second, it is pointed out that dormitories are not clean; there are full of insects [Imperi] despite the use of insecticides prior to the commencement of the training.

As far as hygiene and sanitation is concerned, during focus group discussions, nearly all participants mentioned that there are serious problems. In particular, it is mentioned that it is not easy to find clean water. Subsequently, while HSLs manage to ensure personal hygiene, it is extremely difficult to maintain hygiene in common places, such as bathrooms, toilets, dormitories and lecture halls. Besides, the number of toilets and bathrooms is limited.

It is the opinion of the researchers that the quality of accommodation and the issue of cleanliness may vary from site to site. Since training sites are usually boarding school premises, in cases where the hosting school has suitable accommodation and good hygine facilities, there is no problem at all; but when there is deficient accommodation coupled with the issue of congestion, then trainees are affected. Another issue is that though every training site has got a nurse, health care facilities are not adequate or appropriate. During the training, some HSLs get sick and receive mediocre medical attention.

Given the fluctuation in appreciation of food and accommodation, it is difficult to establish whether these items are driving or restraining forces. But it is uncontroversial that poor sanitation on training sites and lack of appropriate health care facilities are restraining forces to the success of the Itorero scheme for HSLs leavers.

\section{DISCUSSION}

Overall, drawing on attitudes of HSLs, the present article reveals that there is a conglomeration of factors influencing the success of citizenship and values education. This study points out mainly the following: trainers' competencies (academic and moral); family background or home environment of trainees; the training environment; and prevailing government narratives and ideologies, i.e., the public discourse mainly in relation to political, economic, social, and cultural matters.

This finding of the present study joins the civic and citizenship contextual framework developed by CIVED and ICCS (Torney-Purta et al. 2001; Schulz et al. 2008). According to the latter, in citizenship and values education the individual student is located within the overlapping contexts of school and home. Both contexts form part of the local community that, in turn, is embedded in the wider sub-national, national, and international contexts (TorneyPurta et al. 2001; Schulz et al. 2008).

At this point, I wish to consider very briefly the following two aspects of the contextual framework for citizenship and values education, which forcefully surface in the present study: 
(i) the role of teachers' or trainers' preparation (recall the issue of sexual abuse and harsh corporal punishment on some training sites); and (ii) the role of family background - consider the issue that parents indoctrinate HSLs with ethnocentric and xenophobic ideas. The choice of these two aspects is also motivated by the fact that though in citizenship and values education the school has been depicted as more influential in its competition with the home background (Hess and Torney, 1967), research shows that family background remains an influential variable, particularly in the political development of adolescents (Schulz et al. 2008).

The existence of various factors influencing citizenship (and values) education has also been pointed out by Quaynor (2015), who recommends willingness to look for civic influences beyond the civics classroom and the school.

The present article shows that there is a tendency to neglect teachers' or trainers' academic qualification and more importantly moral integrity and to assume that everyone can contribute to citizenship and values education. In view of this, based on Kerr's ideas (1999), one can legitimately raise the following questions: Should teachers/trainers in citizenship and values education be generalists or specialists? Is it trivial to envisage initial and in-service training in citizenship and values education for trainers or teachers?

Unfortunately, research shows a rather limited and inconsistent approach to in-service training and professional development in the field of citizenship and values education (Bîrzéa et al. 2004; Eurydice 2005; Huddleston 2005). The argument here is that the neglect of the initial and in-service teacher training compromises the idea that in citizenship and values education the teacher must see him-herself primarily as a role model, not just as a presenter of information or facilitator of discussion (Huddleston 2005). In addition, such neglect ignores the fact that teachers' preparation (pre-service and in-service) relates to students' civic knowledge and engagement (Torney-Purta, Barber and Richardson 2005)

In relation to family background, the present study shows that learners (in our case HSLs) come to school or training sites not as empty slates vis-à-vis citizenship and values education. They come with a large variety of information received mainly at home. In fact, research indicates that in the context of citizenship and values education, home or family contexts and characteristics influence considerably the development of young people's knowledge, competencies, behaviors, attitudes, and beliefs (Kim 2013; Schulz et al. 2008). The idea here is that what is taught at home plays a crucial role in assimilating the civic content provided in schools or other training programs. The challenge therefore lies in harmonizing the content provided in both places.

In terms of evidence, this study has shown that there is a contradiction between Itorero teaching and the socialization at home particularly in relation to the unity of Rwandans. While 
Itorero teaches that Rwandans are one, parents tell their children that this is mere politics; that among Rwandans there are Hutu, Tutsi and Twa. Facing this contradiction, HSLs become confused, understandably. This finding suggests that for citizenship and values education to be a success, schools (in this case NIC) should have a discussion with parents in order to ensure continuity between the civic content provided in schools/training programs and the socialization at home.

\section{CONCLUSION}

Using Lewin's (1951) Force Field Theory of Change, it is noticeable that according to HSLs, the major driving force of Itorero is the content. The latter is appreciated overwhelmingly by nearly all respondents. The content provided in Itorero allows HSLs to: (i) grasp what it takes to be a good Rwandan citizen; (ii) know Rwandan values and taboos; (iii) be purified from ethnic ideologies imposed by parents, and (iv) be familiar with national development programs and policies. A number of restraining forces are also highlighted. These include mainly the quality of trainers (issues of sexual abuse, and harsh forms of corporal punishment); and poor hygiene due to congestion on training sites. Concerns are also raised about food and health care facilities on training sites.

The overall argument of the article is that for the better future of citizenship and values education in post-genocide Rwanda, the identified driving forces have to be reinforced and restraining ones weakened or eliminated. In addition, for optimal results, careful consideration should be given - in order of importance - to the quality of trainers, the content, and the training environement.

\section{NOTES}

1. For details on findings of CIVED (1971) see (i) Torney, Oppenheim and Farnen (1975); and (ii) Walker (1976).

2. In relation to results from the CIVED (1999) see (i) Torney-Purta, Lehmann, Oswald and Schulz (2001); and (ii) Amadeo, Torney-Purta, Lehmann, Husfeldt and Nikolova (2002).

3. Concerning findings of the ICCS (2009) see Schulz, Ainley, Fraillon, Kerr and Losito (2010).

4. Given the nature of its overall assessment, the item "Overal, Itorero training is a success" was not included in PCA and CFA.

5. This means that the item was forming a cluster of its own as one item.

6. This is the CFA model without specification of either means or intercepts.

7. What is apparent here is that though Itorero relatively encourages HSLs to think critically, it also makes them submissive. Reference is made here to teaching about and recruiting members for the ruling party, the Rwandan Patriotic Front (RPF) in the course of the Itorero training for HSLs. This is evidence that Itorero might be Janus-faced. As Mgbako (2005) argues, Itorero apparently serves the purpose to plant the seed of reconciliation, but it seems inclined to disseminate pro-RPF ideology through political indoctrination. 
8. In this study, it becomes apparent that the content, trainers, and training environment account for only 37 per cent of the success of Itorero. This finding suggests that there are other factors influencing Itorero success that the study did not identify; hence the call for further studies.

9. It is difficult to provide the approximate percentage of trainers engaging in these practices; hence the need for further investigation. Suffice it to say that the issue of sexual abuse was raised in four out of five focus group discussions conducted with HSLs. The same concern was also indicated on some questionnaires mainly where HSLs had to highlight things that they disliked most in the course of Itorero training. The issue of harsh corporal punishment was mentioned in all five focus group discussions.

\section{REFERENCES}

Adejumobi, S. 2001. Citizenship, rights and the problem of conflicts and civil wars in Africa. Human Rights Quarterly 23: 148-170.

Amadeo, J., J. Torney-Purta, R. Lehmann, V. Husfeldt and R. Nikolova, R. 2002. Civic knowledge and engagement: An IEA study of upper secondary students in sixteen countries. Amsterdam: IEA.

Arthur, J., I. Davies and C. Hahn. (Eds.). 2008. The SAGE handbook of education for citizenship and democracy. London: SAGE.

Bîrzéa, C., D. Kerr, R. Mikkelsen, I. Froumin, B. Losito, M. Pol and M. Sardo. 2004. All-European study on education for democratic citizenship policies. Strasbourg: Council of Europe.

Carr, W. 1991. Education for citizenship. British Journal of Educational Studies 39(4): 373-385.

Chioncel, N. and T. Jansen. 2004. Reviewing education and training for governance and active citizenship in Europe - A Central and Eastern European perspective. Project RE-ETGACE.

Codère, H. 1973. The biography of an African society. Rwanda 1900-1960. Tervuren: Musée Royal de l'Afrique Centrale.

Davies, L. 2005. Teaching about conflict through citizenship education. International Journal of Citizenship and Teacher Education 1(2): 17-34.

Eurydice. 2005. The information network on education in Europe. Citizenship education at school in Europe. Brussels: European Commission.

Hess, R. D. and J. Torney. 1967. The development of political attitudes in children. Garden City, NY: Anchor.

Huddleston, T. 2005. Teacher training in citizenship education: Training for a new subject or for a new kind of subject? Journal of Social Science Education 4(3): 50-63.

Kabwete Mulinda, C. 2002. La généalogie de l'idée du peuplement du Rwanda: considérations sur l'autochtonie ou l'allochtonie des Rwandais [The genealogy of the idea of settlement in Rwanda: Considerations on indigenousness or allochthony of Rwandans]. In Peuplement du Rwanda. Enjeux et perspectives [People's settlement in Rwanda: Challenges and prospects], ed. F. Rutembesa, E. Ntaganda and J. Murwanashyaka, 49-72. Butare: Editions de l'Université Nationale du Rwanda.

Kerr, D. 1999. Citizenship education in the curriculum: An international review. School Field 10(3/4): 5-32.

Kim, H. R. 2013. "Citizenship education in comparative perspective: Cross-national variation in the effects of family background on adolescents' civic outcomes". $\mathrm{PhD}$ dissertation, University of California.

Law $\mathrm{N}^{\circ} 41 / 2013$ of 16/06/2013. 2013. Establishing the National Itorero Commission and determining its mission, organization and functioning. Rwanda Official Gazette $\mathrm{N}^{\circ} 29$ of 22 July 2013.

Lewin, K. 1951. Field theory in social sciences. New York: Harper and Row.

Maison des Jeunes de Kimisagara. 2008. Rapport de la recherche sur l'ecole traditionnelle du Rwanda (Itorero) [Report of a Research on the Rwandan traditional school (Itorero)]. Kigali: Author. 
Marshall, T. H. 1950. Citizenship and social class and other essays. Cambridge: Cambridge University Press.

Mgbako, C. 2005. Ingando solidarity camps: Reconciliation and political indoctrination in postgenocide Rwanda. Harvard Human Rights Journal 18: 201-224.

National Itorero Commission. 2011. National Itorero Commission strategy. Kigali: Author.

National Itorero Commission. 2012. Volunteerism policy paper. Kigali: Author.

National Unity and Reconciliation Commission. 2009. Itorero ry'Igihugu [National Itorero]. Policy Note and Strategic Plan. Kigali: Author.

Ndaruhutse, E. 2008. "Les compagnies 'Amatorero' au Rwanda ancien et contemporain" "Amatorero" camps in ancient and contemporary Rwanda]. Honours research project, Kigali Institute of Education.

NIC see National Itorero Commission.

NURC see National Unity and Reconciliation Commission.

Oliver, D., and D. Heater. 1994. The foundations of citizenship. Hertfordshire: Harvester Wheatsheaf.

Prunier, G. 1995. The Rwanda crisis. History of a genocide. Columbia University Press.

Quaynor, L. J. 2015. Researching citizenship education in Africa: Considerations from Ghana and Liberia. Research in Comparative and International Education 10(1): 120-134.

Ramphele, M. 2001. Citizenship challenges for South Africa's young democracy. Daedalus 130(1): 117.

REB see Rwanda Education Board.

Riesenberg, P. 1992. Citizenship in the western tradition: Plato to Rousseau. Chapel Hill: University of North Carolina Press.

Rwanda Education Board. 2015. Competence-based curriculum. Kigali: Author.

Schulz, W., J. Ainley, J. Fraillon, D. Kerr and B. Losito. 2010. ICCS 2009 international report: Civic knowledge, attitudes and engagement among lower secondary school students in thirty-eight countries. Amsterdam: IEA Secretariat.

Schulz, W., J. Fraillon, J. Ainley, B. Losito, and D. Kerr. 2008. International civic and citizenship education study: Assessment framework. Amsterdam: IEA.

Sundberg, M. 2014. Training for model citizenship: An ethnography of civic education and state-making in Rwanda. PhD dissertation. Uppsala University.

Torney, J. V., A. N. Oppenheim and R. F. Farnen. 1975. Civic education in ten countries: An empirical study. Stockholm/New York: Almqvist \& Wiksell International/John Wiley and Sons.

Torney-Purta, J., R. Lehmann, H. Oswald, and W. Schulz. 2001. Citizenship and education in twentyeight countries: Civic knowledge and engagement at age fourteen. Amsterdam: IEA Secretariat.

Torney-Purta, J., C. H. Barber and W. K. Richardson. 2005. How teachers' preparation relates to students' civic knowledge and engagement in the United States: Analysis from the IEA civic education study. CIRCLE Fact Sheet. Center for Information and Research on Civic Learning and Engagement (CIRCLE), University of Maryland.

Van Gunsteren, H. 1998. A theory of citizenship: Organizing plurality in contemporary democracies. Westview Press.

Vansina, J. 2004. Antecedents to modern Rwanda: The Nyiginya kingdom. Madison: University of Wisconsin Press.

Walker, D. A. 1976. The IEA Six Subject Survey: An empirical study of education in twenty-one countries. Stockholm/New York: Almqvist \& Wiksell International/John Wiley and Sons.

Wayne, R. E. 2004. Negotiating the politics of citizenship education. Political Science and Politics 37(2): 249-251. 


\section{Appendix A: Questionnaire for HSLs}

Name of the University:

Gender: Male $\square$

Female:

Age:

Marital status: Single $\square$

Married $\square$

I underwent Itorero training in the year :

I was trained in the Sector.

District.

Province.

Using this scale, kindly express your opinion on the following statements about the Itorero training phase for high school leavers (Tick $\downarrow$ ).

\begin{tabular}{|c|c|c|c|c|c|}
\hline 1 = Strongly disagree & 2 = Disagree & $3=$ Agree & \multicolumn{3}{|c|}{4 = Strongly agree } \\
\hline \multicolumn{2}{|c|}{ Statements } & $\begin{array}{l}\text { Strongly } \\
\text { disagree }\end{array}$ & Disagree & Agree & $\begin{array}{l}\text { Strongly } \\
\text { agree }\end{array}$ \\
\hline 1. Overall, the Itorer & ing was a success. & 1 & 2 & 3 & 4 \\
\hline \multicolumn{2}{|c|}{$\begin{array}{l}\text { to be a good Rwandan citizen. } \\
\text { to know what it takes }\end{array}$} & 1 & 2 & 3 & 4 \\
\hline \multicolumn{2}{|c|}{$\begin{array}{l}\text { 3. The content gave me better knowledge of Rwandan } \\
\text { values and interdictions. }\end{array}$} & 1 & 2 & 3 & 4 \\
\hline \multicolumn{2}{|c|}{$\begin{array}{l}\text { 4. Trainers used appropriate approaches to deliver the } \\
\text { content. }\end{array}$} & 1 & 2 & 3 & 4 \\
\hline \multicolumn{2}{|c|}{ 5. The number of trainers was sufficient. } & 1 & 2 & 3 & 4 \\
\hline \multicolumn{2}{|c|}{$\begin{array}{l}\text { 6. I had the required prerequisites to understand the } \\
\text { content. }\end{array}$} & 1 & 2 & 3 & 4 \\
\hline \multicolumn{2}{|c|}{$\begin{array}{l}\text { 7. I was inconvenienced by the large number of } \\
\text { participants. }\end{array}$} & 1 & 2 & 3 & 4 \\
\hline \multicolumn{2}{|c|}{$\begin{array}{l}\text { 8. The training environment in terms of food was } \\
\text { adequate. }\end{array}$} & 1 & 2 & 3 & 4 \\
\hline \multicolumn{2}{|c|}{ 9. The accommodation provided was comfortable. } & 1 & 2 & 3 & 4 \\
\hline \multicolumn{2}{|c|}{ 10. The duration allocated to the training was adequate. } & 1 & 2 & 3 & 4 \\
\hline \multicolumn{2}{|c|}{ 11. The training encouraged discussion and deliberation. } & 1 & 2 & 3 & 4 \\
\hline \multicolumn{2}{|c|}{ 12. The training enhanced my critical thinking skills. } & 1 & 2 & 3 & 4 \\
\hline
\end{tabular}

\section{Appendix B: The four-factor structure on attitudes of HSLs}

\begin{tabular}{l|l}
\hline Factor 1: Content & Loadings \\
\hline 1. Knowledge of Rwandan values and taboos & .81 \\
2. Knowledge of being a good Rwandan citizen & .81 \\
3. Encouragement of critical thinking skills & .75 \\
\hline Factor 2: Training environment & Loadings \\
\hline 1. Comfortable accommodation & .85 \\
2. Adequate food & .85 \\
\hline Factor 3: Trainers & Loadings \\
\hline 1. Sufficiency in number & .80 \\
2. Use of appropriate approaches & .78 \\
\hline Factor 4: Organization & Loadings \\
\hline 1. Duration adequacy & .84 \\
2. Encouragement of discussion and deliberation & .64 \\
\hline
\end{tabular}


Appendix C: The four-factor CFA model on attitudes of HSLs

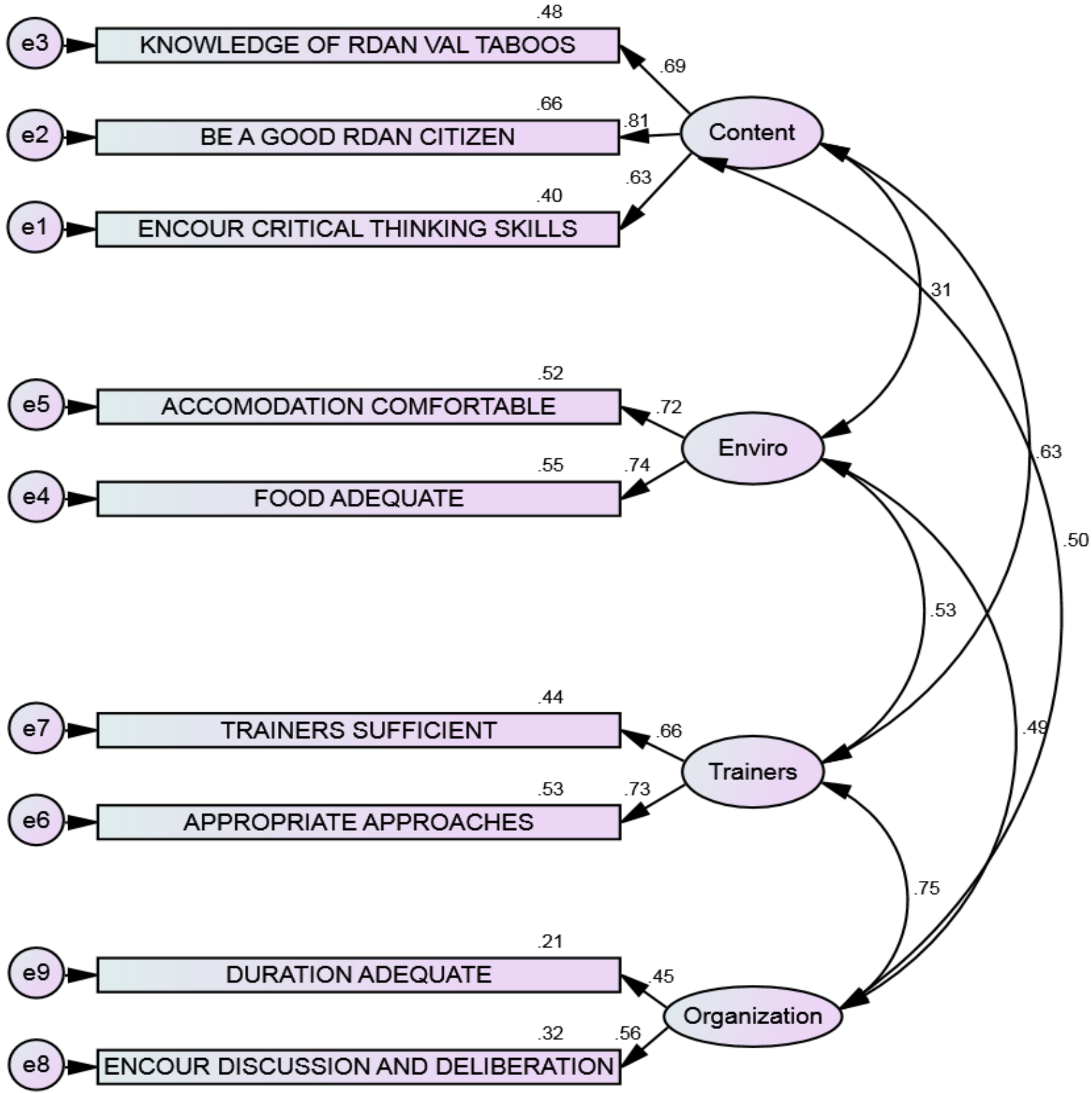

